\title{
Hypocarbia and cystic periventricular leukomalacia in premature infants
}

\author{
Shinji Fujimoto, Hajime Togari, Nobuyuki Yamaguchi, Fumihiko Mizutani, \\ Shigesumi Suzuki, Hisanori Sobajima
}

\begin{abstract}
One hundred sixty seven survivors among very low birthweight infants with a gestational age of less than 35 weeks have been studied prospectively. The purpose of this study was to clarify the relationship of severe prenatal and perinatal complications and hypocarbic alkalosis, defined as a carbon dioxide tension $\left(\mathrm{PaCO}_{2}\right)$ of less than or equal to $2.67 \mathrm{kPa}$ and a $\mathrm{pH}$ of 7.50 or greater during the first 24 hours of life, to cystic periventricular leukomalacia (PVL) depicted by serial cranial ultrasonographic examinations. Complications occurred in 16 infants, five of whom presented with PVL, while eight of 151 infants without complications had PVL. Twenty six of the infants had hypocarbic alkalosis, six with evidence of PVL, and seven of the 136 infants without hypocarbic alkalosis had PVL. These results suggest a significant relationship of complications and hypocarbic alkalosis to PVL. Mechanical ventilation should be managed carefully in premature infants to avoid $\mathrm{PaCO}_{2}$ of lower than $2.67 \mathrm{kPa}$.

(Arch Dis Child 1994; 71: F107-F110)
\end{abstract}

Periventricular leukomalacia (PVL), probably the result of watershed infarction in the periventricular region, is recognised as an important cause of cerebral palsy in preterm infants. ${ }^{1}$ Cystic PVL can now be routinely diagnosed using real time ultrasound in the neonatal intensive care unit (NICU). However, there is little knowledge of the relationship between clinical risk factors and the occurrence of PVL. ${ }^{2} 3$

From the retrospective study of 32 infants with cystic PVL, we recognised two clinically different groups. ${ }^{4}$ One group had a history of severe prenatal or perinatal clinical complications; the other group had no such history, but often had an associated hypocarbic alkalosis within the first 24 hours of life. Therefore, we proposed the following hypotheses before undertaking the present study. (1) Severe complications in utero or within 24 hours of birth are related to cystic PVL. (2) In infants without severe prenatal and perinatal complications, hypocarbia is associated with the occurrence of cystic PVL. To clarify these hypotheses, we undertook the present multicentre prospective study of very low birthweight infants whose gestational age was less than 35 weeks.
Subjects and methods

STUDY POPULATION

The data presented in this report are derived from a prospective study of 167 infants with a birth weight of less than $1500 \mathrm{~g}$ and a gestational age of less than 35 weeks at birth. The study was carried out during the 12 month period between March 1989 and February 1990 in nine NICUs Nagoya City University Medical School, Aichi Prefectural Colony Central Hospital, Ichinomiya City Hospital, Kainan Hospital, Nagoya City Johoku Municipal Hospital, Seirei-Hamamatsu Hospital, Toyohashi Municipal Hospital, Nagoya Seirei Hospital, Nagoya Daini Red Cross Hospital) in the Tokai district in central Japan. During the study period, 191 very low birthweight infants without chromosomal anomaly and less than 35 weeks of gestational age were admitted to these NICUs. Twenty four infants who died within 28 days of age were excluded from the present study, because cyst formation on ultrasound was not identified because of early death. One hundred sixty seven infants were enrolled in the study.

\section{ULTRASONOGRAPHY}

Serial cranial ultrasound examinations were performed within three days of birth, weekly until 1 month of age, then once in two weeks until 2 months, and at discharge. Ultrasound machines used in these NICUs were mainly Hewlett Packard 77020A, U-sonic model RT 3000, Toshiba Sonolayer-S, YHP Sonos 500 and Aloka SSD- $118 \mathrm{~F}$ with 5.0 or $7 \cdot 5 \mathrm{~Hz}$ transducer heads. All ultrasound records were recorded and stored on videotape or film. Two of the authors (SF, NY) reviewed all of the records.

Intracranial findings detected by ultrasonographic scans were classified into the following three categories. (1) 'Cystic PVL' (defined as increased echogenicity in the periventricular region with cyst formation). (2) Other parenchymal lesions (areas of increased echodensity within the cerebral parenchyma other than the periventricular region, resolving echofree cavities; these include parenchymal haemorrhage). (3) Periventricular haemorrhage (increased echogenicity in the region of the germinal matrix or within the lateral ventricles with or without ventricular distension). A prolonged flare $^{5}$ was excluded from abnormal ultrasonographic findings.

\section{CLINICAL AND LABORATORY DATA}

Gestational age was determined from maternal dates or, when necessary, from prenatal 
ultrasound findings in the first trimester. The results of arterial blood gases performed during the first 24 hours of life were analysed. 'Hypocarbic alkalosis' was defined as a $\mathrm{pH}$ of 7.50 or higher and a carbon dioxide tension $\left(\mathrm{PaCO}_{2}\right)$ of $2 \cdot 67 \mathrm{kPa}$ or less. 'Severe prenatal or perinatal complications' included the following conditions: intrauterine infections, intrauterine death of another fetus in multiple gestations, antepartum haemorrhage or preeclampsia requiring emergency caesarean delivery, severe perinatal asphyxia requiring resuscitation, and state of shock during the first 24 hours of life. Use of mechanical ventilation for three hours or less during the first 24 hours of life was not included in the definition of 'mechanical ventilation'. The following clinical events occurring within the first 28 days of life were recorded prospectively: (1) sepsis; defined clinically, including positive and negative blood cultures; (2) symptomatic patent ductus arteriosus (characteristic pansystolic murmur with the treatment by drugs or surgery); (3) pneumothorax; (4) necrotising enterocolitis; and (5) respiratory distress syndrome. All infants with respiratory distress syndrome and some with other respiratory diseases were treated with bovine surfactant.

\section{STATISTICAL ANALYSIS}

Mean values were compared using the Wilcoxon and Mann-Whitney tests. When comparing differences in proportions, Fisher's exact test or the $\chi^{2}$ test with Yates's correction

Table 1 Clinical features and ultrasonographic findings of infants with and without prenatal or perinatal complications

\begin{tabular}{lccc}
\hline & \multicolumn{2}{c}{ Complication } & \\
\cline { 2 - 3 } & Yes $(n=16)$ & No $(n=151)$ & p Value \\
\hline Boys/girls & $8 / 8$ & $75 / 76$ & $>0.05$ \\
Birth weight (g) $_{\text {Gestational age (weeks) }}^{\star}$ & $1117(304)$ & $1138(253)$ & $>0.05$ \\
Apgar score (1 min) & $29 \cdot 4(2 \cdot 2)$ & $29 \cdot 1(2 \cdot 7)$ & $>0.05$ \\
Mechanically ventilated & $2 \cdot 7(2 \cdot 4)$ & $5.9(2.4)$ & $<0.0001$ \\
Outborn/inborn & 16 & 108 & 0.03 \\
Cystic PVL (\%) & $7 / 9$ & $87 / 64$ & $>0.05$ \\
Parenchymal lesions (\%) & $5(31)$ & $8(5)$ & 0.001 \\
Periventricular haemorrhage (\%) & $2(12)$ & $8(5)$ & $>0.05$ \\
& $7(44)$ & $25(17)$ & 0.02 \\
\hline
\end{tabular}

^Mean (SD).

Table 2 Clinical features and ultrasonographic findings of infants with and without hypocarbic alkalosis ${ }^{\star}$

\begin{tabular}{lccc}
\hline & & \multicolumn{2}{l}{ No hypocarbic alkalosis } \\
\cline { 2 - 4 } & $\begin{array}{c}\text { Hypocarbic } \\
\text { alkalosis } \\
(n=26)\end{array}$ & $\begin{array}{l}\text { All } \\
(n=136)\end{array}$ & $\begin{array}{l}\text { Mechanically } \\
\text { ventilated only } \\
(n=98)\end{array}$ \\
\hline Boys/girls & $10 / 16$ & $71 / 65$ & $53 / 45$ \\
Birth weight (g) $\dagger$ & $1043(272)$ & $1146(253)$ & $1080(251)$ \\
Gestational age (weeks) $\dagger$ & $28 \cdot 2(1 \cdot 8)$ & $29 \cdot 2(2 \cdot 7) \ddagger$ & $28 \cdot 2(2 \cdot 2)$ \\
Apgar score (1 min) $\dagger$ & $5 \cdot 2(2 \cdot 9)$ & $5 \cdot 6(2 \cdot 6)$ & $4 \cdot 8(2 \cdot 4)$ \\
Mechanically ventilated & 26 & 985 & 98 \\
Respiratory distress syndrome & 6 & 44 & 44 \\
Sepsis & 1 & 11 & 9 \\
Outborn/inborn & $15 / 11$ & $77 / 59$ & $56 / 42$ \\
No of blood samples $\dagger$ & $4 \cdot 7(2 \cdot 2)$ & $4 \cdot 4(2 \cdot 5)$ & $5 \cdot 3(2 \cdot 3)$ \\
Small for gestational age & 4 & 24 & 9 \\
Cystic PVL & 6 & 75 & $6 \ddagger$ \\
Parenchymal lesions & 2 & 8 & 23 \\
Periventricular haemorrhage & 5 & 27 &
\end{tabular}

*Five patients, who did not have blood gas analysis because of their good condition, were excluded from this analysis. †Mean (SD). $\neq \mathrm{p}<0.05, \S \mathrm{p}<0.01$. was used as appropriate. A value of $p<0.05$ was considered significant.

\section{Results}

Thirteen infants had cystic PVL identified on ultrasound. Twelve of them were diagnosed between 10 and 26 days of age (mean 18 days). Another infant, who had no ultrasound examination between 3 and 7 weeks, was diagnosed at 56 days of age. In addition, 10 infants had other parenchymal lesions and 32 had periventricular haemorrhage.

EFFECT OF PRENATAL AND PERINATAL COMPLICATIONS

Sixteen infants $(9.6 \%)$ in this study had prenatal or perinatal complications (complication group); the other 151 did not (noncomplication group). The complication group had the following problems: six infants with perinatal asphyxia requiring resuscitation, five emergency caesarean deliveries due to antepartum haemorrhage or pre-eclampsia, three intrauterine death of another fetus in multiple gestations, one congenital rubella syndrome, and one infant with shock due to intra-abdominal haemorrhage at 15 hours of life. Table 1 presents a comparison in the two groups of the clinical manifestations and the frequency of cystic PVL, other parenchymal lesions, and periventricular haemorrhage. The complication group demonstrated a significantly higher incidence of cystic PVL $(31 \%$ v $5 \%, \mathrm{p}=0.001)$ and periventricular haemorrhage $(44 \% v 17 \%, \mathrm{p}=0.02)$ than the non-complication group. With the exception of the Apgar score at 1 minute $(p<0.0001)$ and use of mechanical ventilation $(p=0.03)$, there were no significant differences in clinical manifestations between the two groups.

EFFECT OF HYPOCARBIC ALKALOSIS

Five patients, who did not have blood gas analysis because of their good condition, were excluded from this analysis. In the remaining 162 infants, $26(16.0 \%)$ had hypocarbic alkalosis during the first 24 hours of life (hypocarbic group) and 136 did not (nonhypocarbic group). Table 2 presents a comparison of clinical manifestations and the frequency of cystic PVL, periventricular haemorrhage, and other parenchymal lesions in the two groups. The hypocarbic group had a significantly higher incidence of cystic PVL $(23 \% v 5 \%, p=0.007)$ than the nonhypocarbic group. There were significant differences between the two groups for gestational age $(p<0.05)$ and the use of mechanical ventilation $(p<0.01)$. Further comparison of the hypocarbic group to the non-hypocarbic group with mechanical ventilation $(n=98)$ showed no differences among clinical manifestations, except for the incidence of cystic PVL $(23 \% v 6 \%, \mathrm{p}=0.03)$.

The clinical features and laboratory data of infants with cystic PVL and those without cystic PVL in the hypocarbic group are 
Table 3 Characteristics of the infants with hypocarbic alkalosis with and without cystic PVL (there were no significant differences between the two groups)

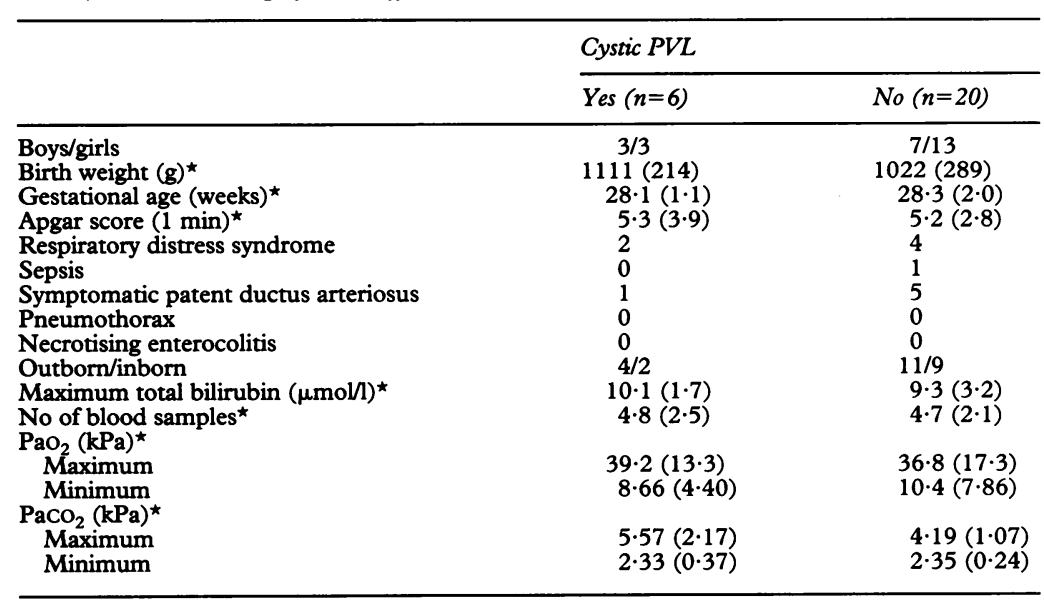

${ }^{\star}$ Mean (SD). $\mathrm{PaO}_{2}=$ oxygen tension.

shown in table 3. There were no significant differences between the two groups. No infant with cystic PVL had both prenatal or perinatal complication and hypocarbic alkalosis.

\section{Discussion}

The most critical pathogenetic factor in PVL is ischaemia to the periventricular region, which is the arterial border zone or end zone in the preterm infant. ${ }^{6}$ Although little work has been done in establishing the risk factors associated with PVL, most studies have demonstrated that the causative insults in the development of PVL occurred in the perinatal or the early postnatal period. Antepartum haemorrhage, birth asphyxia, hypercarbia, sepsis, necrotising enterocolitis, and surgery are known as the major risk factors for PVL. 2378 On the other hand, Volpe states that infants with PVL may be divided into two groups: one group with a history of neonatal clinical complications, the other group more often with none. ${ }^{9}$ The former showed the foregoing risk factors, while it is not clear what factors are at work in the latter group. From our retrospective study, we assumed hypocarbia to be an important risk factor for cystic PVL in the latter group.

The present study showed a significant relationship between severe prenatal or perinatal complications and the occurrence of cystic PVL. Although these results were similar to previous reports, ${ }^{3}$ such complications accounted for less than half of the infants with cystic PVL. Infants with such complications may well develop severe hypotension and decreased cerebral blood flow early in life. Because the methods of recording blood pressure are not necessarily uniform in the participating institutes, we were unable to define the criteria for hypotension in the present study.

Twenty six of the infants without such complications had hypocarbic alkalosis, six with evidence of cystic PVL, while seven of the 136 infants without hypocarbic alkalosis had cystic PVL. There was a strong correlation between hypocarbia and the occurrence of cystic PVL $(p=0.007)$. Some studies have described hypocarbia as a risk factor of PVL or cerebral palsy. Calvert et al demonstrated that infants with cystic PVL had lower mean $\mathrm{PaCO}_{2}$ values and longer periods of low $\mathrm{PaCO}_{2}$ through their retrospective study. ${ }^{10}$ Greisen et al suggested a relationship between severe hypocarbia $\left(\mathrm{PaCO}_{2}\right.$ $<2.00 \mathrm{kPa}$ ) during the first days of life and later brain damage, although the numbers were small. 1112 Ikonen et al revealed that the duration of moderate hypocarbia $\left(\mathrm{PaCO}_{2} \leqslant 4.00\right.$ $\mathrm{kPa}$ ) during the first three days was significantly related to PVL. ${ }^{13}$ Our report is the first prospective study that reveals an association between cystic PVL and severe hypocarbia.

The partial pressures of arterial carbon dioxide have been well known to have an important influence on the regulation of cerebral blood flow. Hypocarbia results in vascoconstriction and decrease of cerebral blood flow. Most studies in animals suggest that cerebral blood flow-carbon dioxide sensitivity in the neonate is less than in the adult. ${ }^{14}$ In preterm infants, Leahy et al suggested that carbon dioxide is an important regulator of cerebral blood flow and that cerebral blood flow-carbon dioxide sensitivity may be higher than that of the adult. ${ }^{14}$ Hansen et al demonstrated that cerebral blood flow in the newborn piglet, comparable with a human infant of 36-38 weeks' gestation, did not decrease significantly from baseline values until extreme degrees of hypocarbia $\left(\mathrm{PaCO}_{2} \leqslant 2.00 \mathrm{kPa}\right)$ were achieved. ${ }^{15}$ In very premature human newborns such as the infants under study, it remains unknown to what degree hypocarbia significantly decreases cerebral blood flow. Our results suggested that a $\mathrm{PaCO}_{2}$ of less than $2.67 \mathrm{kPa}$ may lead to cystic changes in the periventricular region.

As to the cause of hypocarbia, the possibility that an initial insult could result in hyperventilation may be excluded, as no infant without use of mechanical ventilation had hypocarbic alkalosis. It is suggested that excessive settings of the mechanical ventilator lead to hypocarbia in these infants. Overexpansion of the lung due to excessive ventilator setting may also contribute to the development of brain ischaemia possibly via decreased venous return and subsequent decreased cardiac output.

Two infants with PVL demonstrated neither prenatal or perinatal complications nor hypocarbic alkalosis during the first 24 hours of life. One infant fell into a shock followed by pneumothorax at 48 hours. Another infant did not need mechanical ventilation early in life and had no known risk factors for PVL.

Our study excluded cases of neonatal death because cyst formations on ultrasound were not identified due to early death (median age of death 3 days of age). In fact, none of the 24 infants who died in the neonatal period had cystic PVL. We also excluded 'prolonged flare' as a cranial ultrasound finding because there is no consistent relationship to prognosis ${ }^{1}$ and its definition was not consistent among the hospitals in this multicentre study.

It may be difficult to avoid prenatal or perinatal complications such as antepartum haemorrhage and occasional perinatal asphyxia. We recommend that mechanical 
ventilation in premature infants should be managed carefully to avoid a $\mathrm{PaCO}_{2}$ lower than about $2 \cdot 67 \mathrm{kPa}$.

We thank the nursing and medical staff of the nine hospitals participating in this study for their generous assistance and participating in this study for their generous assistance and
cooperation. We thank Professor Yoshiro Wada for his invaluable advice. Gratitude is also expressed to Dr Yasuhiro Hasegawa for his advice on the statistical analysis.

1 Graham M, Levene MI, Trounce JQ, Rutter N. Prediction of cerebral palsy in very low birthweight infants: prospective ultrasound study. Lancet 1987; ii: 593-6.

2 Trounce JQ Shaw DE, Levene MI, Rutter N. Clinical risk factors and periventricular leucomalacia. Arch Dis Child 1988; 63: 17-22.

3 Sinha SK, Davies JM, Sims DG, Chiswick ML. Relation between periventricular haemorrhage and ischaemic brain lesions diagnosed by ultrasound in very pre-term infants. Lancet 1985; ii: 1154-5.

4 Fujimoto S, Katoh I, Okajima K, et al. Thirty-two cases of premature infants with periventricular leukomalacia. Acta premature infants with periventricular leuk

5 Trounce JQ, Rutter N, Levene MI. Periventricular leukomalacia and intraventricular haemorrhage in the preterm neonate. Arch Dis Child 1986; 61: 1196-202.

6 Takashima S, Tanaka K. Development of cerebrovascular architecture and its relationship to periventricular leukomalacia. Arch Neurol 1978; 35: 11-6.
7 De Vries LS, Larroche JC, Levene MI. Cerebral ischaemic lesions. In: Levene MI, Bennett MJ, Punt J, eds. Fetal and neonatal neurology and neurosurgery. Edinburgh: Churchill Livingstone, 1988: 326-38.

8 Low JA, Froese AF, Galbraith RS, Sauerbrei EE, McKinven JP, Karchmar EJ. The association of fetal and newborn metabolic acidosis with severe periventricular leukomalacia in the preterm newborn. Am 7 Obstet Gynecol 1990; 162: 977-82.

9 Volpe JJ. Hypoxic-ischemic encephalopathy. Neurology of the newborn. Philadelphia: WB Saunders, 1987: 220-6.

10 Calvert SA, Hoskins EM, Fong KW, Forsyth SC. Etiologic factors associated with the development of periventricular leukomalacia. Acta Paediatrica Scandinavica 1987; 76: leukom

11 Greisen G, Munck H, Lou H. May hypocarbia cause ischaemic brain damage in the preterm infant? Lancet 1986; ii: 460 .

12 Greisen G, Munck H, Lou H. Severe hypocarbia in preterm infants and neurodevelopmental deficit. Acta Paediatrica Scandinavica 1987; 76: 401-4.

13 Ikonen RS, Janas MO, Koivikko MJ, Laippala P, Kuusinen EJ. Hyperbilirubinemia, hypocarbia and periventricular leukomalacia in preterm infants: relationship to cerebral palsy. Acta Paediatr 1992; 81: 802-7.

14 Leahy FAN, Cates D, MacCallum M, Rigatto H. Effect of $\mathrm{CO}_{2}$ and $100 \% \mathrm{O}_{2}$ on cerebral blood flow in preterm infants. F Appl Physiol 1980; 48: 468-74

15 Hansen NB, Brubakk AM, Bratlid D, Oh W, Stonestreet BS. The effects of variations in $\mathrm{PaCO}_{2}$ on brain blood flow and cardiac output in the newborn piglet. Pediatr Res 1984; 18: 1132-6. 